\title{
Aterrizando el debate sobre la minería en América Latina
}

Raúl Delgado Wise

TRADUCCIÓN DEL INGLÉS DE LUIS RODOLFO MORÁN QUUROZ

En el contexto del boom minero de la primera década del siglo XXI, ha habido un diluvio de publicaciones sobre el nuevo extractivismo y la reprimerazación de las economías latinoamericanas, donde la penetración del capital minero canadiense se pinta frecuentemente como una forma de imperialismo. Sin menospreciar la magnitud y naturaleza de este fenómeno, se argumenta que el capital minero no se ubica en la vanguardia del imperialismo contemporáneo y que conforma una modalidad de capitalismo rentista.

- De qué manera la minería se ajusta a la estrate$<$ gia dominante de reestructuración que siguen las grandes corporaciones multinacionales en la época neoliberal? Para abordar esta pregunta es necesario comenzar con unas cuantas observaciones generales respecto al capitalismo contemporáneo. En otros lugares he argumentado que la actual estrategia de internalización del capital se caracteriza por el establecimiento de redes globales de capital monopólico. Esta estrategia implica que, por medio de las operaciones de subcontratación (outsourcing), las grandes corporaciones multinacionales amplían parte de sus actividades productivas, comerciales, financieras y de servicio a regiones periféricas en busca de fuerza de trabajo barata y flexible, así como de recursos naturales. Esta nueva arquitectura global conlleva el establecimiento de plataformas de exportación que operan como enclaves en los países periféricos. Se estima que alrededor de 85 millones de trabajadores del Sur trabajan en estas plataformas de exportación, sin considerar el sector agrícola. 
Más recientemente, esta estrategia de internacionalización se ha ampliado a la esfera de la innovación científica y tecnológica. A través del acceso a una fuerza de trabajo altamente calificada de las naciones periféricas, las grandes corporaciones multinacionales logran reducir los costos de la fuerza de trabajo, transferir la cobertura del riesgo y las obligaciones y capitalizar los beneficios visibles por medio de la concentración de las patentes. Esto da lugar a una tendencia expansiva en la mercantilización del trabajo científico con una visión a corto plazo y poca consideración de las cuestiones sociales.

En el núcleo de este proceso, que implica un ataque a las condiciones de trabajo y de vida de la mayoría de la clase trabajadora, hay dos factores que lo facilitan: 1) la exagerada sobreoferta de mano de obra. Con la incorporación de Rusia, China e India al mercado capitalista mundial, la oferta de fuerza laboral para el capital creció a más del doble, aumentando de 1.5 miles de millones a 3.1 miles de millones, y 2) la ventaja de buscar el pago de salarios más bajos en el extranjero como una fuente de ganancias extraordinarias. Esto ha llevado a rendimientos monopólicos extraordinarios (rentas imperiales) aprovechando los enormes diferenciales salariales existentes en el mundo: los salarios por hora en China en promedio representan 4\% de los vigentes en Estados Unidos y 16\% de los salarios en México. Como corolario, según las cifras de la Organización Internacional del Trabajo (OIT), en la actualidad hay 1.5 miles de millones de trabajadores sujetos a condiciones de empleo vulnerable; más de 900 millones ganan sueldos de dos o menos dólares estadounideneses diarios y 203 millones están desempleados.

Volviendo a la pregunta planteada al inicio: aunque la minería es un componente de la globalización neoliberal, argumento que no es su fuerza impulsora. Según la lista de Forbes, existen 115 corporaciones mineras entre las dos mil corporaciones más grandes en el mundo. La primera es de Luxemburgo y ocupa la posición 38, Brasil tiene a la segunda corporación minera en tamaño (76 en la lista) y seis más que van de las posiciones 809 a 1971. Canadá tiene la décimo cuarta corporación minera en magnitud: Barrick Gold, situada en el 454 lugar. Hay otras ocho firmas canadienses en la lista, incluyendo Teck Cominco y Gold Corp, que fluctúan entre las posiciones 612 a 1557; México tiene dos corporaciones mineras en la lista: Grupo México (mejor posicionado que Gold Corp, la mayor firma canadiense en México) y Peñoles. Chile tiene una, National Copper Corporation, y Perú también una, Buenaventura.
$\mathrm{Al}$ respecto, es importante reconocer que las corporaciones mineras no se ubican entre las corporaciones multinacionales de mayor tamaño en el mundo y que la posición de las corporaciones canadienses no constituyen la vanguardia corporativa, ni siquiera en América Latina. Al menos debemos ser conscientes de que no se trata de la fracción dominante del capital minero en tres países: Brasil, Chile y México, los que, por cierto, son los productores mineros de mayor magnitud en el subcontinente. Esto, por supuesto, no disminuye la importancia del extractivismo imperialista canadiense; más bien apunta a equilibrar su análisis.

Otro tema importante es que la mayor parte de las corporaciones mineras canadienses se concentran en la producción de oro. En lo que respecta a este metal precioso en particular, Canadá está a la cabeza a nivel global: $75 \%$ de las compañías mineras de oro tienen su sede en ese país, aunque la mayor parte de sus recursos están distribuidos en el exterior. Esto plantea al menos tres temas críticos. Primero, dado que el oro sigue siendo un refugio para el capital monetario (particularmente dada la actual tendencia hacia la financiarización), su capacidad de robustecer enormes cantidades de ganancias extraordinarias en forma de renta absoluta y monopólica refuerza la naturaleza rentista del capital extractivista canadiense. Segundo, el capital minero, es claro, no se ubica en la vanguardia del imperialismo contemporáneo. Tiene una posición limitada frente al capital industrial-financiero. La estrategia de reestructuración de las grandes corporaciones transnacionales - como mencioné antes - se basa más en la ventaja de buscar ganancias extraordinarias aprovechando la fuerza de trabajo barata y flexible, basándose en mecanismos de sobreexplotación. Tercero, el capital minero canadiense tiene ventajas tecnológicas en las actividades de exploración que son esenciales en la minería de oro y metales preciosos. Las actividades de extracción, en mayor o menor medida, tienen importantes costos ambientales. Las corporaciones canadienses han optado, en casi todas las ocasiones, por la minería a cielo abierto, que es la menos costosa, permite una producción a gran escala en un marco temporal breve, pero conlleva impactos ambientales devastadores con severas consecuencias sociales para las comunidades locales.

¿Es la minería una modalidad de capitalismo rentista? En mi opinión, claramente lo es. Implica la apropiación de ganancias extraordinarias en forma de renta de la tierra (es decir, por medio de un valor no creado 
aunque implica un menor grado de saqueo por las grandes corporaciones mineras, no escapa a esta tendencia. Debido a «la confianza en la inversión extranjera para la explotación y el desarrollo de las reservas de recursos naturales del país», como argumenta Veltmeyer, ${ }^{1}$ hay una coincidencia de intereses entre los países latinoamericanos posneoliberales y protosocialistas y el capital extractivo multinacional. Sin embargo, hay otros varios temas que en mi opinión requieren mayor aclaración.

¿Es posible superar la dependencia en la inversión extranjera directa (IED) de las corporaciones mineras internacionales? ¿Cuáles son los márgenes reales de ma- niobra que tienen los gobiernos progresistas para confrontar el voraz apetito del capital minero imperialista canadiense? ¿Qué papel pueden desempeñar los Estados progresistas en América Latina para impulsar procesos de transformación social, verdaderamente emancipadores, antiimperialistas y antisistémicos, en vez de operar como intermediarios del capital minero imperialista canadiense? Además, dada la importante participación de las corporaciones mineras con capital basado nacionalmente en países como Brasil, México, Chile y Perú, ¿cuál es el peso real y la importancia estratégica de las corporaciones mineras canadienses en América Latina?

REFERENCIA

1 Henry Veltmeyer, «Economía política de la extracción de recursos naturales: ¿nuevo modelo de desarrollo o imperialismo extractivista?», Estudios Críticos del Desarrollo, volumen 3, número 4, p. 20.

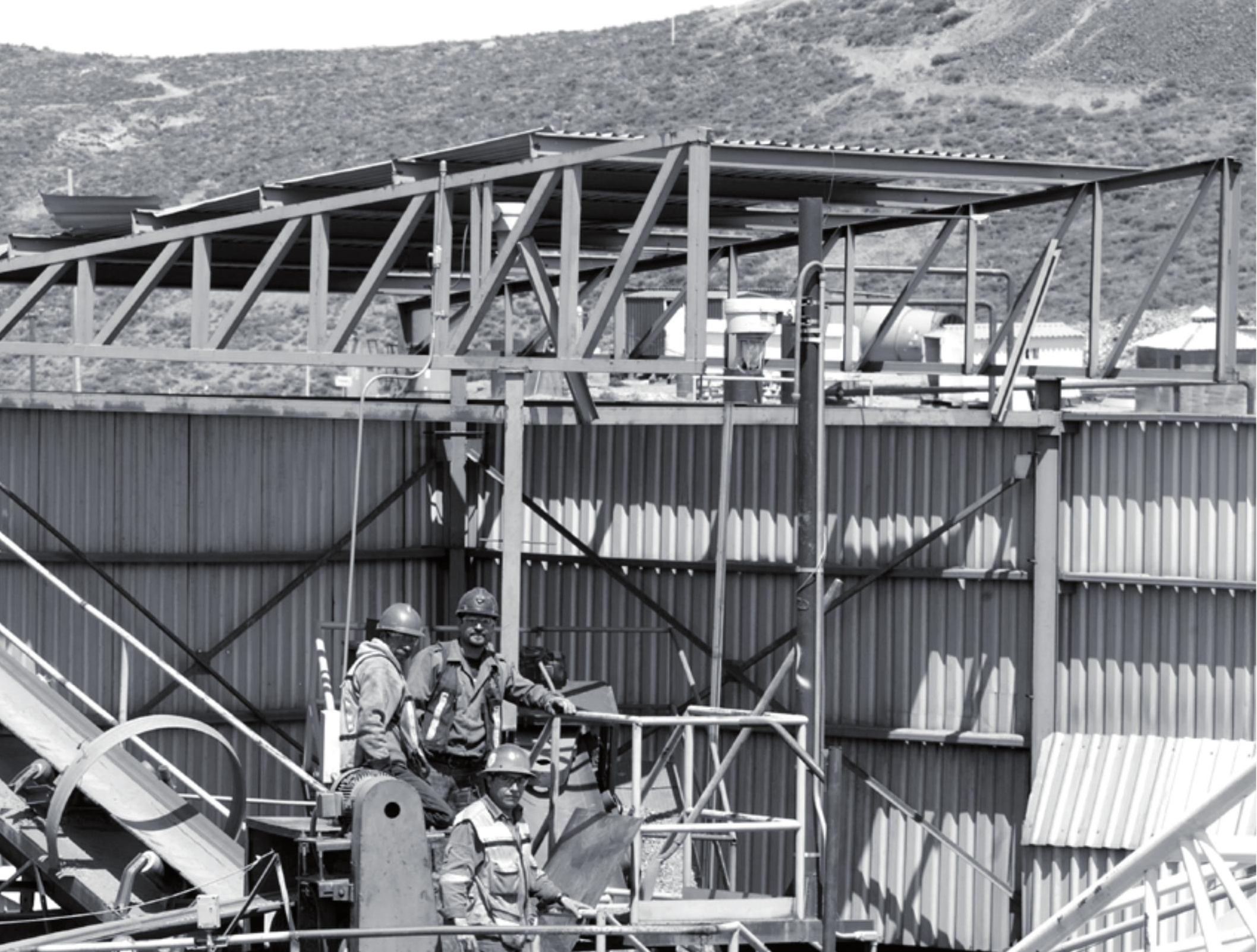

